\title{
Literature review of best health and social care practices for individuals with intellectual disabilities encountering the end of life
}

\author{
Annette Sterling Welch and Carlos Moreno-Leguizamon* \\ Department of Psychology, Social Work and Counselling, University of Greenwich, London SE9 2UG, UK
}

\begin{abstract}
This Literature Review (LR) aimed to identity what were care best practices for individuals with intellectual disabilities (ID) encountering the end of life. Five EBSCOhost academic databases were used to choose thirty primary research articles, from which four emergent themes were identified: (1) end-of-life care approaches, policies and guidelines; (2) challenges experienced by members of the health and social care team; (3) the importance, challenges and benefits of communication; and (4) examples of good practice including rounded end-of-life care that emphasises working collaboratively and inclusively with family and friends. Further, overall findings revealed that there was an absence of policies, procedures and guidelines governing these critical end-of-life care practices, including decision making processes. This means that committed members of the health and social care team working to engage with and support individuals with intellectual disabilities at the end of life are habitually underprepared as they lack appropriate communication skills, experience of dealing with death, relevant training and formal support. On top of this, the LR indicated that there was inadequate collaborative, interagency and multi-professional working. This requires also the integration of the views of the individual with disabilities into models of care, using plain language when communicating with them, especially when breaking bad news that extents to their families and friends. Similarly, the provision of integrated services that respects and fosters autonomy of the dying person with intellectual disabilities. Finally, the LR noted an absence of theory and universal good practice guidance/frameworks on dying, death and intellectual disabilities, and calls for future research framed within the human rights approach.
\end{abstract}

\section{Background}

Members of the health and social care team often encounter difficulties in communicating effectively with people with intellectual disabilities [1]. These communication problems become more pronounced and are infused with greater significance when the individual with an intellectual disability requires end-of-life care at a time when $\mathrm{s} /$ he is most vulnerable and often undergoing both physical and psychological changes. In such circumstances, it is important that the members of the health and social care team are able to understand the wishes and fears of the person requiring care. The person centred care principle makes it incumbent also for this team to support the autonomy of individuals under their care including individuals with intellectual disabilities at the end of life by involving them as fully as possible in the decision making process regarding their care and support. It too involves working collaboratively and supportively with the family or friends of the dying person.

Aside from the inherent difficulties routinely encountered when trying to communicate effectively with an individual with intellectual disability and the often emotionally fraught circumstances at the end-of-life stage, health and social care team members also face a myriad professional challenges. These include attempting to provide care within a responsive, collaborative and inclusive person centred approach in the absence of, or limited, specific policies, procedures, knowledge, training, preparation and support. Further, this situation is exacerbated in the current economic climate in which health and particularly social care are struggling to cope without sufficient resources. A survey completed by almost 150 directors of adult social services in local authorities in England indicated that there was going to be a $£ 1.1$ bn shortfall to social services budgets between 2015 and 2016 , on top of the $£ 4.6$ bn cuts since 2010 [2].

One of the consequences of the deep budget cuts is a reduction in services [3], with a knock-on effect of increasing demand from a growing population on already overstretched resources [4]. The cuts are having deleterious effects on many vulnerable people requiring social care [5], including people with intellectual disabilities. The cuts in central government funding and local authority social care spending are having negative impacts on health and social care provision in England. Understaffed, under resourced and under prepared health and social care team members are in trying circumstances as they attempt to adhere to professional standards and ethics of care whilst being wary of falling victim to the blame culture. Taken together, these factors present substantial challenges to the provision of high quality and responsive care to individuals with intellectual disabilities at the end of life. It is within this context as background that this LR sought to gain a deeper understanding of the range of approaches, policies, practices and challenges involved in the provision of end-of-life care

Correspondence to: Carlos Moreno-Leguizamon, Department of Psychology, Social Work and Counselling, University of Greenwich, London SE9 2UG, UK, Tel: 4402083319306; E-mail: C.J.Moreno@greenwich.ac.uk

Key words: intellectual disabilities, end of life care, health and social care practice, England

Received: September 04, 2016; Accepted: September 28, 2016; Published: September 30, 2016 
for people with intellectual disabilities in order to identify best practice, enhance the quality and responsiveness of care, and better respect the autonomy of those requiring care. Ultimately the question guiding the review was to know how health and social care team members can deliver end-of-life care provision that respects the autonomy, life values and wishes of people with intellectual disabilities.

\section{Methods}

Inasmuch as a "comprehensive study and interpretation of literature that relates to a particular topic" is concerned, a LR contributes to both answering a research question and achieving the aim "by searching for and analysing relevant literature using a systematic approach" [6]. As Hart suggests [7], a literature review should be comprehensive, contain interpretation rather than mere description, each article should be relevant to answering the research question and achieving the research aim, and a systematic, consistent and coherent approach should be employed in searching for, selecting and analysing literature.

Thus, whilst carrying out background reading before the literature search, it became apparent that clarity about the type of research would be helpful in selecting the most appropriate search methods for answering/achieving the research question/aim [7]. provides a typology of research types including: basic, applied, summative evaluation, formative evaluation, action research, illuminative evaluation and ethnomethodology. Illuminative evaluation was considered here the most appropriate, since this aims to inform policy makers and/or practitioners about ways in which activities carried out in comparable settings can be enhanced.

\section{Search strategies}

A number of literature search strategies were considered: starting, browsing, chaining, forward citation, scanning, contacting scholars and keywords. Starting refers to the identification of possible sources of interest by searching the internet for main research terms [8]. In this instance, for example, intellectual disability and end-of-life care. Browsing, which involves scanning the titles and/or tables of contents of potentially useful literature, was helpful in provoking thinking about the topic as well as finding material [9]. Chaining or 'backward snowballing' involves looking up references found in relevant articles on the research topic $[8,10]$. Forward citation searching or 'forward snowballing' involves selecting seminal articles and looking for studies citing those articles [10]. Scanning involves the checking of bibliographic databases and/or the bibliographies of existing literature reviews for sources that may be pertinent to the research topic. Alternatively, it is possible to make contact with prominent scholars in the particular field. Using keywords within pre-set parameters focuses the search, refines the search results and eliminates irrelevant sources [11]. In this particular case the strategies of starting, browsing, scanning and contacting scholars were unnecessary. The keyword search was deemed to be the most beneficial in this case because it enabled specificity through the combining of search terms.

\section{Keyword search}

Systematicity in literature searching informed the search, which began with identifying key variables/terms in the project's research question and research aim; along with this, a search for alternative terms/synonyms and related terms was conducted as suggested by [6] (Table 1). This was followed by brainstorming and mind-mapping to extend the range of potential search terms (Table 2). Further, five online information databases were selected from EBSCHOhost online
Table 1. Keywords from research question and aim.

\begin{tabular}{|l|l|}
\hline Question/aim keywords & Alternatives and related \\
\hline Health & - \\
\hline 'Social care' & - \\
\hline 'Intellectual disabilit' & 'Learning disabilit'' \\
\hline $\begin{array}{l}\text { 'End of Life' OR 'End- } \\
\text { of-Life' }\end{array}$ & Death OR dying \\
\hline Decision" & - \\
\hline Autonom" & IgnityOR respect \\
\hline 'Life values' & $\begin{array}{l}\text { Beliefs OR ethics OR integrity OR morals OR ideals OR } \\
\text { honour }\end{array}$ \\
\hline Approach" & - \\
\hline Policies or policy & Strategy OR procedure OR plan OR program" \\
\hline Practice & Activit" OR system OR method" \\
\hline Challenge* & Problem" OR difficult' OR testing OR demanding \\
\hline 'Best practice' & $\begin{array}{l}\text { 'Good practice' OR effective OR 'high quality' OR 'high } \\
\text { standard' }\end{array}$ \\
\hline Communicat" & Interact" \\
\hline 'Care quality' & 'Quality care' \\
\hline Responsive & 'Individual" care' OR 'person centred' OR 'sensitive care' \\
\hline
\end{tabular}

Table 2. Keywords from brainstorming and mind-mapping.

\begin{tabular}{|c|c|}
\hline Brainstormed words & Mind-mapped words \\
\hline Famil $^{*}$ & Relations* or relatives* or kin* or personal or intimate or friends \\
\hline Staff" & Workers* or professionals* \\
\hline Train* & Teach" or educat" or coach" or guid" or instruct ${ }^{*}$ \\
\hline Awareness* & Understand $^{*}$ \\
\hline Support ${ }^{*}$ & Encourage* or guid* \\
\hline Collaborat* & Partner" or cooperat" or assist or inter-profession" or multi-profession" \\
\hline Stress & Pressure" OR strain OR anxi" OR tension \\
\hline Prepared* & Equipped or ready or provision \\
\hline Ethics & Principles or code or standard \\
\hline
\end{tabular}

information resources for the keyword search. These were Academic Search Complete, CINAHL Plus, Education Research Complete, ERIC, and PsychARTICLES.

\section{Limiters/focussing parameters and booleans}

Prior to commencing the search, limiters or focussing parameters were selected that narrowed the scope of the search and removed sources unlikely to be directly relevant to the research topic [12]. The limiters used were PDF Full Text, Scholarly (Peer Reviewed) Journals, References Available, Published Date, Document Type, Language, Abstract Available, Exclude Book Reviews, Exclude Non-Article Content, Population Group and Age Groups.

A series of complex searches was carried out using two or more of the keywords [13]. After spending considerable time combining different keywords, it became apparent that the most efficient search combination was 'intellectual disabilit*' AND 'end-of-life'. This was used in combination with keywords contained in the tables above. Thus, the research articles were selected if they contained the keywords and were directly relevant to answering the research question and achieving the research aim. A landmark study was identified for each theme and subtheme. "Landmark studies are significant research projects that generate knowledge that influences a discipline and sometimes society as a whole" [13]. The limited literature on intellectual disability and end-oflife care is such that a judgement was made about whether an article was particularly relevant to answering/achieving the research question/aim to the extent that it discussed a particular theme and identified subthemes. 


\section{Results}

Thirty articles were selected for inclusion in this LR, from which four emergent themes were identified. These were: (1) end-of-life care approaches, policies and guidelines; (2) challenges experienced by members of the health and social care team trying to provide high quality, responsive, person-centred care to people with intellectual disabilities at the end of life; (3) the importance, challenges and benefits of communication in providing care to people with intellectual disabilities at the end of life; and (4) examples of good practice that include placing a high value on holistic end-of-life care that emphasises working collaboratively and inclusively with family and friends. The second theme - challenges - is a portmanteau category containing multiple factors including lack of training, inexperience in dealing with death, and insufficient support in managing their own, and others', grief.

\section{Approaches, policies, guidelines and practices}

A study of the experiences of health and social care staff in dealing with issues surrounding dying and death in the care and support of people with intellectual disabilities [14] conducted in-depth interviews with 22 individuals across five health providers. The dominant theme emerging from the study was the commitment staff have to being there', caring for and supporting people with intellectual disabilities through three stages: dying, death and beyond death. Being there for the person with an intellectual disability after death involved dealing with the corpse, being involved in planning funerals and keeping the person alive socially through remembrance. Researchers support the holistic approach asserting that working with and researching people with intellectual disability should be viewed as being from the cradle to the grave [15]. A content analysis of policy documents on end-of-life decisions regarding persons with intellectual disabilities from 25 residential care facilities in the Netherlands [16] identified two decision-making categories: palliative sedation and withholding/ withdrawing life-sustaining treatment. Perhaps the most telling findings from this research is that, although the cross-sectional mail survey data collection instrument was sent to 140 organisations, less than $20 \%$ (n25) provided copies of polices, and that the contents of the policies were vague in relation to people with intellectual disabilities. A similar study retrospectively analysing the medical files of 47 people with intellectual disabilities who had died in a Dutch residential centre, found that end-of-life decisions were taken in 27 cases [17]. Whilst the family was involved in approximately half of the cases, the study did not find evidence of involvement of any of people with intellectual disabilities in the decision making affecting their end of life. Taken together, the findings, analyses and conclusions from [14-17] suggest that either there was an absence of policies and procedures governing these critical end-of-life care decision making processes or an update of policies and procedures in the context of autonomy and human rights.

In developing guidelines governing the disclosure/non-disclosure of life-limiting illness and impending death of people with intellectual disabilities, authors [18] highlight the absence of policies and procedures in this area of end-of-life care and support. Focus groups and semi structured interviews were conducted with 109 research participants: people with intellectual disabilities, family members and professionals specialising with intellectual disabilities. In making the decision, the guidance includes assessing the person's decision making capacity, making best interest decisions by listening to family and carers, following the person's wishes, and assessing the relative merits of disclosure/non-disclosure. As in the case in relation to end-of-life decision making, there is an absence of policy and procedure about whether or not, or how much, to disclose to people with intellectual disabilities at the end of life. Nevertheless, the guidelines are indicative of good practice. So the question here is, whether this is exclusive to the disable community, or if it applies as well to other communities, for example, in which ethnicity, gender, sexual orientation, age, or income level is present.

\section{Challenges and needs of End-of-Life care providers}

Members of the health and social care team participating in research regarding the development of partnerships identified three categories of challenges in providing end-of-life care for people with disabilities: marginalisation, inequity of access and inadequate coordination [19]. Marginalisation refers to the fact that people with intellectual disabilities are often provided with services that were not specifically developed with their requirements in mind. Whilst people with intellectual disabilities have the theoretical right to receive equitable end-of-life care, the research evidence indicates there is inequitable access and that often people with intellectual disabilities do not benefit from this theoretical right. This supports [20] the assertion that people with intellectual disabilities are presented with many obstacles in accessing good quality health and social care at the end of life. Thus, even before care can be provided, many people with intellectual disabilities have to overcome barriers to access. Those working with people with intellectual disabilities and their families and friends at the end of life would do well to bear this in mind.

Many members of the health and social care team are underprepared for caring for people with intellectual disabilities at the end-of-life as they do not have experience of dealing with death [21]. Research also found [22] that staff did not feel properly prepared to meet the needs of people with intellectual disabilities at the end of life. This in turn contributed to staff experiencing elevated levels of stress, particularly when there were challenging decisions to be taken, when staff felt excluded by service users' family members and when staff had insufficient time or support to deliver care and/or mourn the death of service users.

A 14 focus group study investigating the care concerns of health and social care team members working with individuals with intellectual disabilities and late-stage dementia identified lack of knowledge and skills in caring for people with intellectual disabilities and dementia, culturally competent caring, addressing hydration/nutrition and pain anxieties, delivering palliative care and facilitating grief and loss as the key emergent themes [23]. A resultant training course addressing the highlighted issues was regarded as highly valuable by staff, particularly in relation to support for staff, family and peers in dealing with bereavement and grief. A trainer manual was developed supporting in-service training on dementia in people with intellectual disabilities across six service providers. This is particularly important as it appears to be common for there to be a lack of training in providing end-of-life care for people with intellectual disabilities [23-25].

Numerous studies identify and discuss the challenges in involving the family of people with intellectual disabilities in end-of-life care planning and decision making [26-29]. There were also challenges in working strategically, collaboratively and effectively with other professionals, whether in the same or different provider organisations $[19,20,30-33]$. The lack of guidance in policy and procedures is another challenge as was addressed earlier.

Some researchers [34] problematise the issue of communication 
asserting that, on the one hand, health and social care team members want to communicate in the styles preferred by individuals with intellectual disabilities, yet, on the other, to do so often entails being in conflict with organisational policy and practice. This suggests that organisational policies that do exist may have an inward focus rather than focussing on the best interests of those requiring care. Situations like this present frontline staff with major professional and ethical dilemmas.

\section{Communication}

Continuing with the theme of communicational challenges, a qualitative multiple case study involving semi structured interviews with professional and familial caregivers of 12 recently deceased individuals with intellectual disabilities found that the interviewees were challenged primarily by issues concerned with communication [26,35]. These included finding out the information requirements of the persons with intellectual disabilities, communicating to the dying individuals about illness and death, and ascertaining their explicit and tacit wishes. Communication is particularly important, as it is central to ascertaining the information needs and end-of-life wishes of the dying person with an intellectual disability, both of which are integral to respecting autonomy $[26,35]$.

Challenging communication and comprehension issues are well documented elsewhere in the literature $[1,24]$. Some researchers [36] maintain that it is common for people with intellectual disabilities not to tell those caring for them, both professionals and family, that they are in pain. This is compounded as members of the health and social care team do not habitually use communication tools, and insufficient attention is given to adjusting for communication problems and difficulties in understanding. If health and social care professionals are aware of these difficulties, they can make preparations to augment communication. An example of this is the use of pictures as communication aids. Understanding and responding appropriately to cues is critical to successful communication and interactions with people with intellectual disabilities [1]. The authors also draw attention to the fact that people with intellectual disabilities have difficulty comprehending members of the health and social care team, particularly when there is an overreliance on verbal communication and language that are not adjusted to the levels of understanding of people with intellectual disabilities. This is significant as people with intellectual disabilities often use non-verbal cues that require nonverbal responses. Tuffrey-Wijne and McEnhill [37] point out that it is difficult to provide good quality palliative care when communication is time consuming and ineffective because of lack of understanding. Moreover, this contributes to inadequate assessment and undermines the quality of psychosocial support $[20,37]$.

\section{Good practice}

Writing from the perspectives of individuals with intellectual disabilities, [38] identify a number of characteristics of care quality. These include integrated provision, accessibility, continuity, seamless transitions and flexibility. Respecting and fostering the autonomy of the dying person with an intellectual disability is fundamental to care quality and good practice [26] as is the fostering of high quality relationships with people with intellectual disabilities at the end of life $[1,27,28,33,38,39]$. This includes the active integration of the views of service users into models of care [40,41]. A necessary component of this which has been addressed earlier is enhancing the quality of communication [42]. In so doing, it is important to use plain, unambiguous language, introducing oneself to the person with an intellectual disability, being clear about the purpose of the interaction and being 'patient' [37]. This is particularly important when breaking bad news. When breaking bad news to a person with an intellectual disability, the author [43] advocates 'building a foundation of knowledge' in which information is broken down into small, discrete chunks that can be built on over time, taking into account the capacity of the individual and the support available. Working collaboratively with family, including post-bereavement support is another component of good practice [27-29,38]. Interagency and multi-professional partnership working is also identified as good practice in providing end-of-life care and services to people with intellectual disabilities $[19,27,28,32,33]$.

All of these characteristics are premised on care being evidencebased [33] and on staff being prepared through the provision of adequate knowledge, training and management support $[22,23,25]$.

\section{Discussion}

Overall this LR has revealed that there are three main types of challenges - communication, knowledge and skills, and inexperience of dealing with dying, death and grief in a professional context. Taken together, the three categories of challenges mean that members of the health and social care team are often unprepared and unsupported during highly emotional, demanding and traumatic times. This in turn negatively affects their professional performance in three distinct ways. First, it limits their ability to respect and foster the autonomy, integrity, life values and final wishes of people with intellectual disabilities at their end of life. Second, it makes it difficult for them to engage collaboratively and supportively with family and friends of the dying persons with intellectual disabilities. Third, and often underappreciated and/or overlooked, it leaves them vulnerable to recognising and managing their own grief, feelings of helplessness and stress; all of which are highly detrimental to their psychosocial wellbeing. The use of medical humanities seems significant here as it can introduce how to handle issues of uncertainty and/or compassion and self-compassion [44].

The fulsome and creative support of senior management is also essential to achieving best practice. For example, in a time of diminishing resources, in particular finance and staff, senior management could follow the advice of [19] in initiating interagency and multi-professional partnership working in the area of information and training on end-of-life care and services for individuals with intellectual disabilities.

One of the challenges in undertaking this LR was the dearth of theoretical literature on the provision of end-of-life care for people with intellectual disabilities from the perspective of either inequalities in health or intersectionality. The current research is overwhelmingly experiential and is practically focused, addressing the challenges and experiences faced by people with intellectual disabilities, their families and friends, and the staff endeavouring to provide responsive, high quality care at a significant and difficult life stage.

In general, the lack of literature is indicative of the challenges faced by health and social care team members attempting to care for vulnerable people at the end of life. In the study on research about death, dying and intellectual disability, Todd et al. $[14,15]$ pointed out that it is a $21^{\text {st }}$ century research area which, in the first years of the new century, was still regarded as being "too emotive and certainly too incongruous for intellectual disability researchers" [14]. The authors expand on the general attitudes prevalent amongst bereavement research at the 
beginning of the present century. They note, for example, that not only was death, dying and intellectual disabilities not regarded as a subject meriting scholarly attention, but that short shrift was given to the very idea that the deaths of people with intellectual disabilities could contain powerful meanings for those who loved them. There seemed to have been conceptual and experiential blind spots both within academic and practitioner communities that deaths are mourned in relation to people with intellectual disabilities.

"The idea that people with intellectual disability might leave a social legacy was not entertained. This absence of thought that people with intellectual disability might just leave a gap in society when they die, no doubt, related to the general devaluing of people with intellectual disability, including their relationships with others" [15].

It may well be that one of the factors contributing to this academic and policymaking disinterestedness, is that people with intellectual disabilities were, up until fairly recently, hidden away in institutions. As such, the adage, out of sight, out of mind, may have been applicable. However, a strong theme emerging from the findings of the LR is that those working face to face with people with intellectual disabilities at the end of life are highly engaged and committed to delivering the most responsive and high quality care. Equally, such commitment and efforts are routinely stymied and undermined by the lack of appropriate policy, guidance, information, training and support. This is reflected in the facts that there is limited literature on dying, death and intellectual disabilities and that the literature has not developed, amended or applied theory to the subject.

Fortunately, if some authors [15] are correct, there is an emergent recognition and setting in order of human rights for people with intellectual disabilities that is informing and encouraging ways of addressing social death and closing the time-based gap between social death and physical death. This is reflected in [14] empirical research findings in which members of the health and social care team recognised the importance of 'being there' for people with intellectual disabilities not only whilst they are dying and in the moments of their deaths, but also beyond, through social remembrance. On a less sanguine note, the fact that there are few articles cited in this discussion and that there is significant absence of theory, suggests that the headline findings of the LR should be presented in the form of absences, oversights and inadequacies in terms of policy, commitment and practice on the part of policymakers, senior managers and academics. The LR provides examples of frontline health and social care workers doing what they can whilst being unprepared, underprepared and unsupported to the detriment of people with intellectual disabilities at the end of life.

\section{Conclusion}

This LR research question asked: How can health and social care workers deliver end-of-life care provision that respect the autonomy, life values and wishes of people with intellectual disabilities? One of the main conclusions that provides a partial answer to the question is that members of the health and social care team are committed to delivering responsive end-of-life care, however, without sufficient policy directives, information, guidance, training and formal support. Another way of putting this is that health and social care team members require clear policies, information, guidance, training and formal support from senior management so that they can deliver endof-life care provision that respect the autonomy, life values and wishes of people with intellectual disabilities.

Specifically, the findings from the LR revealed that there is an urgent need for policies, guidance and training on appropriate and effective communication with people with disabilities generally, and at the end of their lives in particular. Many health and social care team members struggle to communicate effectively with people with intellectual disabilities at the end of life, and the knowledge that this is detrimental to the people they are caring for contributes to high levels of stress. Similarly, there are widespread deficiencies in communication and relationships with other professionals both within and across provider organisations. This also undermines the quality of care to people with intellectual disabilities at the end of life.

The LR indicates that good practice includes integrative provision that involves the person with intellectual disabilities, their family and/ or friends and all service providers in decision making about end-oflife care. The sharing and use of evidence-based best practice is vital and would be enhanced by a theoretical base, universal good practice guidance/framework(s), and the unambiguous support of policymakers and senior managers.

In an era in which social care funding has and will continue to be cut with already meagre resources stretched even further, the implications for practice arising out of this LR are bleak. Not only do frontline health and social care team members have responsibility for providing emotion sapping end-of-life care to people with intellectual disabilities and their families, this LR's findings indicate that the responsibility for advocating for more targeted and effective policies, guidance, information, training and support is also on their shoulders.

Finally, future research that develops and/or adapts theory appropriate to dying, death and intellectual disabilities would be beneficial. Similarly, more in-depth research focusing on developing end-of-life care policy and practice guidance would assist in moving research in this area forward. Presenting such research within the rubric of human rights for people with intellectual disabilities may be a means of converting the agendas of decision makers to an ethical basis and thus give due recognition to this extremely important but customarily overlooked subject.

\section{References}

1. Antonsson H, Graneheim U, Lundström M, Åström S (2008) 'Caregivers' reflections on their interactions with adult people with learning disabilities. J Psychiatr Ment Health Nurs 5: 484-491. [Crossref]

2. BBC (2015) Adult social care firms struggling for staff due to cuts. BBC News.

3. McNicoll A (2015) Social workers forced to cut care packages as $£ 1$ bn wiped off social care budgets.

4. Shah N (2016) David Cameron has created a mental health crisis that can't be solved with £1billion worth of funding. The Independent.

5. Samuel M (2015) Enough is enough on social care cuts, sector tells government ahead of spending review. Community Care.

6. Aveyard H (2014) Doing a literature review in health and social care. A practical guide ( $3^{\text {rd }}$ edn), Maidenhead: McGraw-Hill Education, Open University Press.

7. Hart C (1998) Doing a literature review. Releasing the social science research imagination. Sage Publications, London.

8. Choo C, Detlor B, Turnbull D (2000) Information seeking on the web: An integrated model of browsing and searching. First Monday.

9. Sandelowski M, Barros J (2007) Handbook for synthesizing qualitative research. New York: Springer Publishing Company.

10. Jalali S, Wohlin C (2012) Systematic literature studies: Database searches vs. backward snowballing. International Conference on Empirical Software Engineering and Measurement, ESEM'12, Sweden pp: 19-20.

11. Bell J, Waters S (2014) Doing your research project: A guide for first-time researchers ( $6^{\text {th }}$ edn), Maidenhead: Open University Press, McGraw-Hill. 


\section{EBSCOhost Help (2016) Limiters}

13. Burns N, Grove S (2011) Understanding nursing research: Building an evidence-based practice. $\left(5^{\text {th }}\right.$ edn), Maryland Heights: Elsevier Saunders

14. Todd S (2013) Being there': The experiences of staff in dealing with matters of dying and death in services for people with intellectual disabilities. $J$ Appl Res Intellect Disabil 26: 215-230. [Crossref]

15. Todd S, Bernal J, Forrester-Jones R (2013) Death, dying and intellectual disability research. J Appl Res Intellect Disabil 26: 183-185. [Crossref]

16. D'Haene I, Pasman H, Deliens L, Bilse J, Mortier F, et al. (2010) End-of-life care policies in Flemish residential care facilities accommodating persons with intellectual disabilities. J Intellect Disabil Res 54: 1067-1077. [Crossref]

17. Wagemans A, Van Schrojenstein Lantman-de Valk H, Tuffrey-Wijne I, Widdershoven G, Curfs L (2010) End-of-life decisions: An important theme in the care for people with intellectual disabilities. J Intellect Disabil Res 54: 516-524. [Crossref]

18. Tuffrey-Wijne I, Giatras N, Butler G, Cresswell A, Manners P, et al. (2013) Developing guidelines for disclosure or non-disclosure of bad news around life-limiting illness and death to people with intellectual disabilities. J Appl Res Intellect Disabil 26: 231-242. [Crossref]

19. McLaughlin D, Barr O, McIlfatrick S, McConkey R (2014) Developing a best practice model for partnership practice between specialist palliative care and intellectual disability services: A mixed methods study. Palliat Med 28: 1213-1221. [Crossref]

20. Cross H, Cameron M, Marsh S, Tuffrey-Wijne I (2012) Practical approaches toward improving end-of-life care for people with intellectual disabilities: Effectiveness and sustainability. J Palliat Med 15: 322-326. [Crossref]

21. Wiese M, Dew A, Stancliffe R, Howarth G, Balandin S (2013) If and when?: The belief and experiences of community living staff in supporting older people with intellectual disability to know about dying. J Intellect Disabil Res 57: 980-992. [Crossref]

22. Ryan K, Guerin S, Dodd P, McEvoy J (2011) End-of-life care for people with intellectual disabilities: Paid carer perspectives. J Appl Res Intellect Disabil 24: 199-207.

23. Fahey-McCarthy E, McCarron M, Connaire K, McCallion P (2009) Developing an education intervention for staff supporting persons with an intellectual disability and advanced dementia. J Policy Pract Intellect Disabil 6: 267-275.

24. Cooper M, Gambles M, Mason S, McGlinchey T (2014) How confident are nurses that they can provide good care? Learning Disability Practice 17: 34-39.

25. Buntinx W, Schalock R (2010) Models of disability, quality of life, and individualized supports: Implications for professional practice in intellectual disability. J Policy Pract Intellect Disabil 7: 283-294.

26. Bekkema N, de Veer A, Hertogh C, Francke A (2014) Respecting autonomy in the endof-life care of people with intellectual disabilities: a qualitative multiple-case study. $J$ Policy Pract Intellect Disabil 58: 368-380.

27. Wagemans A, Van Schrojenstein Lantman-De Valk H, Proot I, Metsemakers J, TuffreyWijne I, et al. (2013a) The factors affecting end-of-life decision-making by physicians of patients with intellectual disabilities in the Netherlands: a qualitative study. $J$ Intellect Disabil Res 57: 380-389.

28. Wagemans A, Van Schrojenstein Lantman-de Valk H, Proot I, Metsemakers J, Tuffrey-
Wijne I, et al. (2013b) End-of-life decisions for people with intellectual disabilities, an interview study with patient representatives. Palliat Med 27: 765-771. [Crossref]

29. MacHale R, McEvoy J, Tierney E (2009) Caregiver perceptions of the understanding of death and need for bereavement support in adults with intellectual disabilities. $J$ Appl Res Intellect Disabil 22: 574-581.

30. Tuffrey-Wijne I, Curfs L (2013a) The factors affecting end-of-life decision-making by physicians of patients with intellectual disabilities in the Netherlands: a qualitative study. J Intellect Disabil 57: 380-389.

31. Tuffrey-Wijne I, Curfs L (2013b) End-of-life decisions for people with intellectua disabilities, an interview study with patient representatives. Palliat Med 27: 765-771.

32. Clute MA (2010) Bereavement interventions for adults with intellectual disabilities: what works? Omega (Westport) 61: 163-177. [Crossref]

33. McCarron M, McCallion P, Fahey-McCarthy E, Connaire K (2010) Staff perception of essential prerequisites underpinning end-of-life care for persons with intellectual disability and advanced dementia. J Policy Pract Intellect Disabil 7: 143-152.

34. Forster S, Iacono T (2008) Disability support workers' experience of interaction with a person with profound intellectual disability. J Intellect Dev Disabil 33: 137-147. [Crossref]

35. Bekkema N, Veer A, Wagemans A, Hertogh C, Francke A (2015) To move or not to move: A national survey among professionals on beliefs and considerations about the place of end-of-life care for people with intellectual disabilities. J Intellect Disabil Res 59: 226-237. [Crossref]

36. Beacroft M, Dodd K (2011) 'I Feel Pain'-audit of communication skills and understanding of pain and health needs with people with learning disabilities. $\mathrm{Br} J$ Learn Disabil 39: 139-147.

37. Tuffrey-Wijne I, McEnhill L (2008) Communication difficulties and intellectual disability in end-of-life care. Int J Palliat Nurs 14: 189-194. [Crossref]

38. Barelds A, Van De Goor I, Bos M, Van Heck G, Schols J (2009) Care and service trajectories for people with intellectual disabilities: Defining its course and quality determinants from the client's perspective. J Policy Pract Intellect Disabil 6: 163-172.

39. Reinders H (2010) The importance of tacit knowledge in practices of care. J Intellect Disabil Res 54 Suppl 1: 28-37. [Crossref]

40. Forbat L, Wilkinson $H(2008)$ Where should people with dementia live? Using the views of service users to inform models of care. Br J Learn Disabil 36: 6-12.

41. Tuffrey-Wijne I, Bernal J, Butler G, Hollins S, Curfs L (2007) Using Nominal Group Technique to investigate the views of people with intellectual disabilities on end-of-life care provision. J Adv Nurs 58: 80-89. [Crossref]

42. Read S, Nte S, Corcoran P, Stephens R (2013) Using action research to design bereavement software: Engaging people with intellectual disabilities for effective development. J Appl Res Intellect Disabil 26: 195-206. [Crossref]

43. Tuffrey-Wijne I (2013) A new model for breaking bad news to people with intellectual disabilities. Palliat Med 27: 5-12. [Crossref]

44. Moreno-Leguizamon C, Patterson J, Rivadeneira A (2015) Incorporation of socia sciences and humanities in the training of health professionals and practitioners in other ways of knowing. J Med Humanit.

Copyright: $\left({ }^{2} 2016\right.$ Welch AS. This is an open-access article distributed under the terms of the Creative Commons Attribution License, which permits unrestricted use, distribution, and reproduction in any medium, provided the original author and source are credited. 